\title{
Divergent Prelimbic Cortical Pathways Interact with BDNF to Regulate Cocaine-seeking
}

\author{
(1)Giuseppe Giannotti, ${ }^{\star}$ Sarah M. Barry, ${ }^{\star}$ Ben M. Siemsen, - Jamie Peters, and Jacqueline F. McGinty \\ Department of Neuroscience, Medical University of South Carolina, Charleston, South Carolina 29425
}

A single BDNF microinfusion into prelimbic (PrL) cortex immediately after the last cocaine self-administration session decreases relapse to cocaine-seeking. The BDNF effect is blocked by NMDAR antagonists. To determine whether synaptic activity in putative excitatory projection neurons in PrL cortex is sufficient for BDNF's effect on relapse, the PrL cortex of male rats was infused with an inhibitory Designer Receptor Exclusively Activated by Designer Drugs (DREADD) viral vector driven by an $\alpha$ CaMKII promoter. Immediately after the last cocaine self-administration session, rats were injected with clozapine- $\mathrm{N}-0 x i d e 30$ min before an intra-PrL BDNF microinfusion. DREADD-mediated inhibition of the PrL cortex blocked the BDNF-induced decrease in cocaine-seeking after abstinence and cue-induced reinstatement after extinction. Unexpectedly, DREADD inhibition of PrL neurons in PBS-infused rats also reduced cocaine-seeking, suggesting that divergent PrL pathways affect relapse. Next, using a cre-dependent retroviral approach, we tested the ability of DREADD inhibition of PrL projections to the NAc core or the paraventricular thalamic nucleus (PVT) to alter cocaine-seeking in BDNF- and PBS-infused rats. Selective inhibition of the PrL-NAc pathway at the end of cocaine self-administration blocked the BDNF-induced decrease in cocaine-seeking but had no effect in PBS-infused rats. In contrast, selective inhibition of the PrL-PVT pathway in PBS-infused rats decreased cocaine-seeking, and this effect was prevented in BDNF-infused rats. Thus, activity in the PrL-NAc pathway is responsible for the therapeutic effect of BDNF on cocaine-seeking whereas inhibition of activity in the PrL-pPVT pathway elicits a similar therapeutic effect in the absence of BDNF.

Key words: addiction circuitry; chemogenetics; cocaine use disorder; relapse; viral vectors

\section{Significance Statement}

The major issue in cocaine addiction is the high rate of relapse. However, the neuronal pathways governing relapse remain unclear. Using a pathway-specific chemogenetic approach, we found that BDNF differentially regulates two key prelimbic pathways to guide long-term relapse. Infusion of BDNF in the prelimbic cortex during early withdrawal from cocaine self-administration decreases relapse that is prevented when neurons projecting from the prelimbic cortex to the nucleus accumbens core are inhibited. In contrast, BDNF restores relapse when neurons projecting from the prelimbic cortex to the posterior paraventricular thalamic nucleus are inhibited. This study demonstrates that two divergent cortical outputs mediate relapse that is regulated in opposite directions by infusing BDNF in the prelimbic cortex during early withdrawal from cocaine.

\section{Introduction}

Glutamatergic output from the dorsomedial PFC to subcortical regions regulates cognitive, emotional, and motivational pro-

Received May 25, 2018; revised Aug. 21, 2018; accepted Aug. 24, 2018.

Author contributions: G.G. wrote the first draft of the paper; G.G., S.M.B., B.M.S., J.P., and J.F.M. edited the paper; J.P. and J.F.M. designed research; G.G., S.M.B., and B.M.S. performed research; G.G., S.M.B., and J.F.M. analyzed data.

This work was supported by National Institute on Drug Abuse/National Institutes of Health Grants P50 DA15369 and R01 DA033579 to J.F.M., T32 DA07288 and F31 DA039709 to S.M.B., and F31 DA041021 to B.M.S. We thank Jordan Hopkins and Nour Hijazi for excellent technical assistance.

The authors declare no competing financial interests.

*G.G. and S.M.B. contributed equally to this work as dual first authors.

Correspondence should be addressed to Dr. Jacqueline F. McGinty, Department of Neuroscience, Medical Univer-

sity of South Carolina, 173 Ashley Avenue, MSC 510, Charleston, SC 29425. E-mail: mcginty@musc.edu. cesses, including relapse to stimuli predicting the availability of addictive drugs (Moorman et al., 2015; Koob and Volkow, 2016). In rodents, the prelimbic (PrL) subdivision of the PFC has emerged as the primary cortical region that promotes relapse to drug-seeking (Kalivas and Volkow, 2005). Pharmacological or optogenetic inactivation of PrL cortex after extinction training and immediately before various relapse tests decreases cocaineseeking (McFarland and Kalivas, 2001; Stefanik et al., 2016). In contrast, pharmacological inactivation of PrL cortex immediately after the end of cocaine self-administration (SA) has no effect on relapse likely because the predominant effect of cocaine 
is to decrease global neuronal activity and signaling in the PrL cortex (Chang et al., 1998; Go et al., 2016; Dennis et al., 2018). Moreover, within $2 \mathrm{~h}$ after the end of cocaine SA, there is a marked decrease in tyrosine phosphorylation of ERK/MAP kinase and the NMDA receptor subunits, GluN2A and GluN2B (Whitfield et al., 2011; Go et al., 2016). A single intra-PrL microinfusion of BDNF immediately after the last cocaine SA session attenuates subsequent relapse (Berglind et al., 2007) and normalizes phosphorylation of ERK, CREB, GluN2A, and GluN2B (Whitfield et al., 2011; Go et al., 2016). NMDA receptor-mediated synaptic activity within the PrL cortex is essential for BDNFmediated suppression of cocaine-seeking because an intra-PrL microinfusion of either GluN2A or GluN2B inhibitors prevents the BDNF-mediated normalization of NMDAR phosphorylation and blocks the suppressive effect of BDNF on cocaine-seeking (Go et al., 2016). However, NMDA receptors and TrkB, the cognate receptor for BDNF, are expressed by both interneurons and pyramidal projection neurons in the PFC (Povysheva and Johnson, 2012), obscuring the cellular site of action of BDNF. To begin to dissect BDNF's cellular site of action, here we investigated whether BDNF's effect on relapse depends on activity within discrete populations of pyramidal projection neurons in the PFC using a viral vector-mediated DREADD (Designer Receptors Exclusively Activated by Designer Drugs) approach. We found that an inhibitory DREADD (hM4Di) expressed under the control of the $\alpha$ CaMKII promoter, which putatively targets cortical excitatory neurons within the PrL cortex (Dittgen et al., 2004; Nathanson et al., 2009), blocked the BDNF-mediated decrease in cocaine-seeking after abstinence and extinction. Unexpectedly, this DREADD-mediated inhibition in the absence of exogenous BDNF also suppressed relapse, suggesting potential mediation of relapse by divergent PrL pathways. Based on our previous observation that intra-PrL administration of BDNF normalizes the cocaine-induced reduction in extracellular glutamate in the NAc core (Berglind et al., 2009), we selectively inhibited neurons projecting from the PrL cortex to the NAc core before an intra-PrL BDNF infusion. We found that inhibition of PrL-NAc core neurons blocked the BDNF-induced suppression of relapse without affecting relapse in PBS-infused rats, indicating that the $\alpha$ CaMKII-driven hM4Di-mediated decrease in relapse is not mediated by PrL-NAc core pathway inhibition.

To determine what PrL pathway mediates the ability of $\alpha$ CaMKII-driven hM4Di to decrease relapse independently of BDNF, we focused on the paraventricular thalamic nucleus (PVT) for several reasons. First, PVT plays a crucial role in modulating motivational behaviors, including relapse to drug-seeking (James and Dayas, 2013; Kirouac, 2015; Matzeu et al., 2015; Millan et al., 2017; Kuhn et al., 2018). Second, layer VI neurons within the PrL cortex provide a major source of innervation to the PVT (Li and Kirouac, 2012; Millan et al., 2017). Third, distinct neuronal ensembles within the PrL cortex projecting to either NAc core or PVT show opposite neuronal activity in response to reward-associated conditioned cues (Otis et al., 2017). Accordingly, we found that chemogenetic inhibition of PrL neurons projecting to the posterior part of PVT (pPVT) immediately after the last cocaine SA session decreased relapse to cocaineseeking after abstinence and extinction, and this effect was blocked by BDNF.

\section{Materials and Methods}

Animals. Male Sprague Dawley rats $(N=167$, Charles River Laboratories) weighing 275-325 g upon arrival were individually housed in ven- tilated cages in a temperature and humidity-controlled room on a 12:12 reverse light/dark cycle (lights off at 6:00 A.M., lights on at 6:00 P.M.). Rats had ad libitum access to standard rat chow (Harlan) and water before experimental manipulations. All experiments and procedures were conducted during the dark cycle and approved by the Institutional Animal Care and Use Committee of the Medical University of South Carolina and were performed according to the Guide for the care and use of laboratory animals (National Institutes of Health, 2011). In Experiment 1a, 36 rats were divided into 4 groups: eGFP-PBS $(N=11)$, eGFP$\operatorname{BDNF}(N=10)$, hM4Di-PBS $(N=6)$, and hM4Di-BDNF $(N=9)$. In Experiment 1b, 9 rats were divided into 2 groups: eGFP-PBS $(N=5)$ and hM4Di-PBS $(N=4)$. In Experiment 2, 26 rats were divided into 4 groups: mCherry-PBS $(N=7)$, mCherry-BDNF $(N=7)$, hM4Di-PBS $(N=6)$, and hM4Di-BDNF $(N=6)$. In Experiment 3, 38 rats were divided into 4 groups: mCherry-PBS $(N=13)$, mCherry-BDNF $(N=7)$, hM4Di-PBS $(N=11)$, and hM4Di-BDNF $(N=7)$. In Experiment 4,16 rats were divided into 2 groups: mCherry $(N=8)$ and hM4Di $(N=8)$. For Fos analysis in pPVT and PrL cortex, 14 rats were divided into 2 groups: yoked saline $(N=8)$ and cocaine SA $(N=6)$. As specified in Results, we excluded from our analysis 28 rats, due to sickness or infection $(N=6)$, lack of virus expression or missed cannula placement $(N=13)$, lost a head cap $(N=6)$, or statistical outliers $(N=3)$ for a final $N=139$.

Viral vectors. All viral procedures and constructs used in this study were approved by the Medical University of South Carolina Institutional Biosafety Committee. In Experiments $1 \mathrm{a}$ and $1 \mathrm{~b}, \mathrm{AAV} 5-\alpha$ CaMKII-eGFP (titer $4 \times 10^{12} \mathrm{vg} / \mathrm{ml}$ ) and AAV5- $\alpha$ CaMKII-hM4Di-mCherry (titer $4.3 \times 10^{12} \mathrm{vg} / \mathrm{ml}$ ) were obtained from the University of North Carolina viral vector core (Chapel Hill, NC). In Experiments 2, 3, and 4, Credependent viral vectors were purchased from AddGene and were used to selectively infect neurons projecting from the PrL cortex to either the NAc core or PVT. The PrL-injected vectors were AAV5-hSyn-DIOmCherry (titer $4.8 \times 10^{12} \mathrm{vg} / \mathrm{ml}$ ) and AAV5-hSyn-DIO-hM4DimCherry (titer $4.7 \times 10^{12} \mathrm{vg} / \mathrm{ml}$ ). In Experiment 2, a retrogradely transported canine adenovirus type 2 (CAV2) virus expressing a CreeGFP (CAV2-Cre-eGFP) fusion protein under a CMV promoter (titer of $7.3 \times 10^{12} \mathrm{vg} / \mathrm{ml}$, diluted 1:1 in sterile $10 \mathrm{~mm}$ PBS for a final titer of $\sim 3.6 \times 10^{12} \mathrm{vg} / \mathrm{ml}$-Institut de Génétique Moléculaire de Montpellier) was used. In Experiment 3 and 4, a retrogradely transported AAV (AAVrg) (Tervo et al., 2016) expressing a Cre-BFP fusion protein (AAVrg-Cre-BFP) under a pmSyn promoter (titer $5.5 \times 10^{12} \mathrm{vg} / \mathrm{ml}$ AddGene) was used.

Surgical procedures and viral infusions. Rats were anesthetized with a mixture of ketamine $(66 \mathrm{mg} / \mathrm{kg}$, i.p.) and xylazine $(1.33 \mathrm{mg} / \mathrm{kg}$, i.p.) followed by equithesin $(0.5 \mathrm{ml} / \mathrm{kg}$, i.p. $)$ and ketorolac $(2.0 \mathrm{mg} / \mathrm{kg}$, i.p. $)$ to provide analgesia. One end of a Silastic catheter (Thermo Fisher Scientific) was placed into the right jugular vein through a small incision and threaded subcutaneously to an infusion cannula (Plastics One) mounted on the animal's back. The antibiotic cephazolin $(10 \mathrm{mg} / 0.1 \mathrm{ml} ; 0.1 \mathrm{ml}$ i.v.) and the antibacterial solution, taurolidine-citrate catheter solution $(0.05 \mathrm{ml}$ i.v. $)$ were infused after surgery and for $5 \mathrm{~d}$ of recovery. After catheterization, the rats were placed in a stereotaxic apparatus (Kopf Instruments) for intracranial surgeries. In Experiments 1a and 1b, the PrL cortex of rats was bilaterally cannulated with a 26-gauge double barrel steel guide cannula (Plastics One) using the following coordinates relative to bregma: $2.8 \mathrm{~mm}$ anteroposterior, $\pm 0.6 \mathrm{~mm}$ mediolateral, and $-2.8 \mathrm{~mm}$ dorsoventral. Cannulae were anchored to the skull with cranioplastic cement and steel screws (Plastics One). Following 1 week of recovery, rats were lightly anesthetized with ketamine/xylazine, and the PrL cortex was infused bilaterally with $0.75 \mu$ l of AAV5- $\alpha$ CaMKII-eGFP or AAV5- $\alpha$ CaMKII-hM4Di-mCherry using a microinjector (Plastics One) that extended $1 \mathrm{~mm}$ beyond the implanted cannula and a gas-tight Hamilton syringe mounted on a microinfusion pump (Harvard Apparatus). The injectors were left in place for $10 \mathrm{~min}$ to allow for diffusion of the virus. In Experiment 2, the NAc core of rats was infused bilaterally with $0.75 \mu \mathrm{l}$ of CAV2-Cre-eGFP ( $10^{\circ}$ angle, bregma: $1.6 \mathrm{~mm}$ anteroposterior, $\pm 2.8 \mathrm{~mm}$ mediolateral, $-7.1 \mathrm{~mm}$ dorsoventral) using a Nanoject Auto-Nanoliter Injector (Drummond Scientific), and the glass pipettes were left in place for $10 \mathrm{~min}$ to allow for diffusion of the virus. The PrL cortex of rats was then cannulated as described above. After 1 week of 
recovery, the PrL cortex was infused bilaterally with $0.75 \mu$ l of AAV5hSyn-DIO-mCherry or AAV5-hSyn-DIO-hM4Di-mCherry. In Experiment 3 , the PVT of rats was infused with $0.3 \mu \mathrm{l}$ of AAVrg-Cre-BFP $\left(25^{\circ}\right.$ angle, bregma: $-3 \mathrm{~mm}$ anteroposterior, $2.42 \mathrm{~mm}$ mediolateral, -5.74 $\mathrm{mm}$ dorsoventral) with a Nanoject injector, and the PrL cortex was either bilaterally cannulated for later infusion or infused at the time of surgery with $0.75 \mu$ l of AAV5-hSyn-DIO-mCherry or AAV5-hSyn-DIO-hM4DimCherry using the Nanoject injector. In Experiment 4, the PVT of rats was infused with $0.3 \mu \mathrm{l}$ of AAVrg-Cre-BFP, and the PrL cortex was bilaterally infused with $0.75 \mu \mathrm{l}$ of AAV5-hSyn-DIO-mCherry or AAV5hSyn-DIO-hM4Di-mCherry with the Nanoject injector. The infusion rate was $0.15 \mu \mathrm{l}$ per minute in all experiments.

Cocaine SA and post-SA infusions. Following recovery, rats were foodrestricted to $20 \mathrm{~g}$ of chow $1 \mathrm{~d}$ before and during SA training to facilitate learning. Rats were trained to self-administer cocaine on a fixed ratio (FR) 1 schedule of reinforcement during $2 \mathrm{~h}$ sessions for $14 \mathrm{~d}$ in operant boxes housed in sound-attenuating ventilated chambers (Med Associates). Rats were trained to press the active lever to self-administer cocaine hydrochloride (0.2 mg/infusion; NIDA Drug Supply Program) paired with light and tone $(78 \mathrm{db}, 4.5 \mathrm{kHz})$ cues, followed by a $20 \mathrm{~s}$ timeout whereupon an active lever press resulted in no programmed consequences. Pressing the inactive lever had no programmed consequences. SA criterion was set at a minimum of 10 cocaine infusions/d for $14 \mathrm{~d}$. Immediately after the last cocaine SA session, all the animals were injected with $10 \mathrm{mg} / \mathrm{kg}$ (i.p.) of clozapine-N-oxide (CNO-NIDA Drug Supply Program) in 5\% DMSO with $0.9 \%$ sterile saline. This dose of CNO has been effectively used without side effects in several published studies (Mahler et al., 2014; Augur et al., 2016). Thirty minutes later, the PrL cortex of rats was bilaterally infused with $0.5 \mu \mathrm{l}$ BDNF $(0.75 \mu \mathrm{g} / \mu \mathrm{l} /$ side, R\&D Systems) or $10 \mathrm{~mm}$ sterile PBS (rate of $0.25 \mu \mathrm{l} / \mathrm{min}$ ), using an injector that extended $1 \mathrm{~mm}$ below the cannula tip. The injector remained in place for an additional 2 min following infusions.

Abstinence, extinction, and relapse testing. Rats underwent $6 \mathrm{~d}$ of abstinence in their home cages with food ad libitum followed by a $2 \mathrm{~h}$ postabstinence context-induced relapse test (PA test) under extinction conditions, whereupon lever presses were recorded but had no programmed consequences. The PA test represents the first day of extinction training after abstinence in the drug-associated context when cocaineseeking rates are highest. After at least $5 \mathrm{~d}$ of additional extinction training (days $2-6$ ) to a criterion of $<25$ active lever presses for 2 consecutive days, rats underwent a $2 \mathrm{~h}$ cue-induced reinstatement test (cue test) in which an active lever press resulted in presentation of the previously drug-paired cue complex, but no drug infusion, followed by a $20 \mathrm{~s}$ timeout whereupon an active lever press resulted in no programmed consequences. Rats were perfused immediately after the cue test. One week after the cue test, the animals of Experiment $1 \mathrm{~b}$ were used to investigate functionality of $\alpha$ CaMKII-driven hM4Di DREADD. Five rats (eGFP, $N=2$; and hM4Di, $N=3)$ received an injection of CNO $(10 \mathrm{mg} / \mathrm{kg}$, i.p. $)$ $30 \mathrm{~min}$ before an injection of cocaine (10 mg/kg, i.p.), and transcardially perfused $2 \mathrm{~h}$ after the cocaine injection. To investigate Fos induction in the PrL cortex and pPVT, a different cohort of rats underwent cocaine $\mathrm{SA}$, and each rat in the SA group was paired with a yoked-saline rat that received a saline infusion and presentation of conditioned stimuli when the counterpart received an infusion of cocaine. Rats were transcardially perfused $2 \mathrm{~h}$ after the last cocaine SA session.

Sucrose SA and seeking. In Experiment 4, following recovery from viral infusions, rats were food-restricted to $20 \mathrm{~g}$ of chow $1 \mathrm{~d}$ before and during SA training to facilitate learning. Rats were trained to self-administer sucrose on a FR1 schedule of reinforcement for $10 \mathrm{~d}$ ( $2 \mathrm{~h}$ session) in operant chambers (Med Associates). Presses on the active lever resulted in delivery of a single $45 \mathrm{mg}$ chocolate-flavored sucrose pellet (Bio-Serv) paired with light and tone cues $(78 \mathrm{db}, 4.5 \mathrm{kHz})$, followed by a $20 \mathrm{~s}$ time-out whereupon active lever presses were recorded but resulted in no programmed consequences. Immediately after the last sucrose SA session, rats were injected with $\mathrm{CNO}(10 \mathrm{mg} / \mathrm{kg}$, i.p.) as described above. Rats then underwent $6 \mathrm{~d}$ of abstinence in their home cages with food available ad libitum followed by a $2 \mathrm{~h}$ PA test under extinction conditions, extinction to criterion over 5 additional sessions, and a 2 h cue test. Rats were perfused immediately after the cue test.
Immunohistochemistry. Rats were anesthetized with a mixture of ketamine/xylazine and transcardially perfused with ice-cold $0.1 \mathrm{M} \mathrm{PBS,} \mathrm{pH}$ 7.3 , followed by $4 \%$ ice-cold PFA (pH 7.3 in $0.1 \mathrm{~m} \mathrm{PBS}$ ) at a rate of $60-70$ $\mathrm{ml} / \mathrm{min}$. Brains were extracted and postfixed for $1 \mathrm{~h}$ at $4^{\circ} \mathrm{C}$ in $4 \% \mathrm{PFA}$, before transferring them to a $30 \%$ sucrose solution in $0.1 \mathrm{M} \mathrm{PBS}$ for $48 \mathrm{~h}$ at $4^{\circ} \mathrm{C}$. Serial coronal sections $(50-60 \mu \mathrm{m})$ were obtained with a Leica cryostat and collected in chilled $0.1 \mathrm{M}$ PBS containing $0.01 \%$ sodium azide and stored at $4^{\circ} \mathrm{C}$ until processed. Sections were blocked for $2 \mathrm{~h}$ at room temperature in PBS-Triton X-100 (0.3\%, PBS-T) with 2\% normal goat serum (Jackson ImmunoResearch Laboratories) and incubated overnight at room temperature with anti-GFP (Abcam catalog \#ab13970 RRID:AB_300798, 1:1000), anti- $\alpha$ CaMKII (Thermo Fisher Scientific catalog \#MA1-048 RRID:AB_325403, 1:1000), anti-mCherry (LifeSpan, catalog \#LS-C204825, RRID:AB_2716246, 1:1000), anti-Fos (Santa Cruz Biotechnology catalog \#sc-52, RRID:AB_2106783, 1:1000), or anti-BFP (Abcam, catalog \#ab32791, RRID:AB_873781, 1:1000) primary antisera. Sections were washed $3 \times 5$ min with PBS-T, then incubated in speciesspecific secondary antisera. Secondary antisera used were goat antichicken conjugated to AlexaFluor-488 (Abcam catalog \#ab150169, RRID: AB_2636803, 1:1000), goat anti-mouse AlexaFluor-488 (Abcam catalog \#ab150077, RRID:AB_2630356, 1:1000), goat anti-rabbit AlexaFluor-594 (Cell Signaling Technology, catalog \#8889, RRID:AB_2716249, 1:1000), goat anti-chicken AlexaFluor-594 (Abcam, catalog \#ab150176, RRID: AB_2716250, 1:1000), and goat anti-mouse AlexaFluor-647 (Abcam catalog \#ab150115, RRID:AB_2687948) for $2 \mathrm{~h}$ in PBS-T at room temperature. Sections were then washed $3 \times 5 \mathrm{~min}$ in PBS-T, mounted on slides, coverslipped with ProLong Gold anti-fade reagent (Invitrogen), and stored at $4^{\circ} \mathrm{C}$ until imaging.

Confocal microscopy. Images were obtained using a Leica SP5 laser scanning confocal microscope equipped with an argon (Ar $488 \mathrm{~nm}$ ), helium-neon (He-Ne $568 \mathrm{~nm}$ ), and helium-neon (He-Ne $633 \mathrm{~nm}$ ) lasers. For DREADD expression in PrL cortex, AlexaFluor-594-labeled hM4DimCherry was excited using the $568 \mathrm{~nm}$ laser. $z$ stack $(\sim 30 \mu \mathrm{m})$ images were obtained with a $10 \times$ air objective $(1024 \times 1024$ frame size, 12-bit image resolution, 4 frame averages, $1.5 \mu \mathrm{m}$ step size) for each hemisphere, compressed into a single plane and stitched together into a single image using the "Stitching" plugin of ImageJ software (National Institutes of Health). For axon terminal expression and injection site verification, $z$ stack $(\sim 30 \mu \mathrm{m})$ images were obtained at $10 \times$ and compressed into a single plane in ImageJ. In NAc core, AlexaFluor-594-labeled hM4Di-mCherry-expressing terminals were excited using the $568 \mathrm{~nm}$ laser and AlexaFluor-488-labeled eGFP was excited using the $488 \mathrm{~nm}$ laser. For terminal expression and injection site verification in the PVT, AlexaFluor-594-labeled hM4Di-mCherry-expressing terminals were excited using the $568 \mathrm{~nm}$ laser and AlexaFluor-647-labeled BFP was excited using the $633 \mathrm{~nm}$ laser.

Fos quantitation, BFP profile, colocalization analysis, and integrated density. $z$ stack $(\sim 30 \mu \mathrm{m})$ images were captured with a Leica SP5 confocal microscope $(20 \times$ air objective, $1024 \times 1024$ frame size, 12-bit resolution, 4 frame averages, $1.5 \mu \mathrm{m}$ step size). In eGFP-expressing animals, Alexa-594-labeled Fos was excited using the $568 \mathrm{~nm}$ laser. In the hM4DimCherry expressing animals, Alexa-488-labeled Fos was excited using the $488 \mathrm{~nm}$ laser and Alexa-594-labeled hM4Di-mCherry was excited using the $568 \mathrm{~nm}$ laser. Confocal images were then imported into Imaris software (Bitplane), automatic threshold was set, and the number of Fos $^{+}$and hM4Di-mCherry ${ }^{+}$neurons in the PrL cortex, as well as the BFP profile was automatically measured using the Imaris spot detection function. Colocalization analysis was performed using the colocalize spot function in Imaris. The number of $\mathrm{Fos}^{+}$and hM4Di-mCherry ${ }^{+}$neurons, $\mathrm{BFP}$, as well as the number of colocalized spots were then averaged for each hemisphere within each section across 3 or 4 sections per rat. For colocalization analysis of $\alpha$ CaMKII with hM4Di-mCherry, images were captured with $20 \times$ air objective and manual counts were performed on merged $z$ projections from each image by overlaying the sections with a grid and using the counter tool option in ImageJ. Colocalization of hM4Di-mCherry in $\alpha$ CaMKII-positive neurons is expressed as a percentage of mCherry-positive neurons.

For integrated density analysis of virus expression in mPFC (Experiment 1), images were acquired with a Nikon Eclipse E-600 fluorescence 
Experiment 1

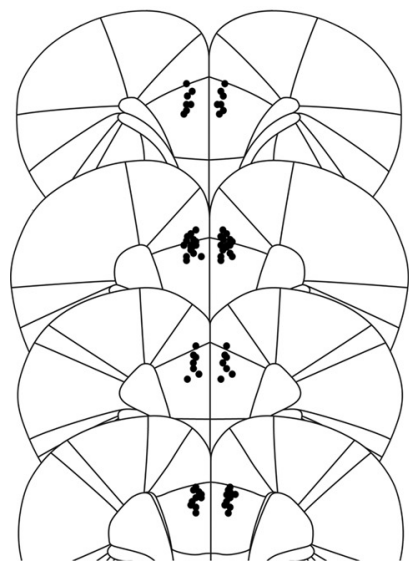

Experiment 2

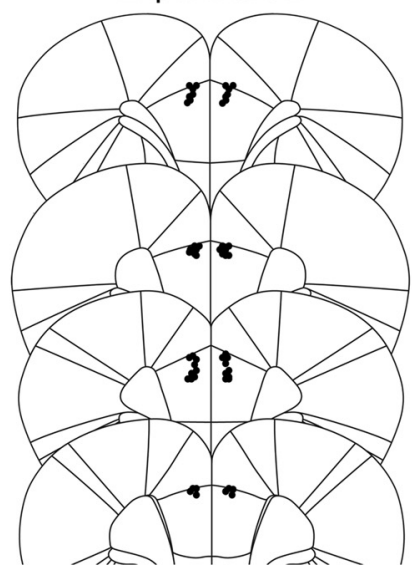

Experiment 3

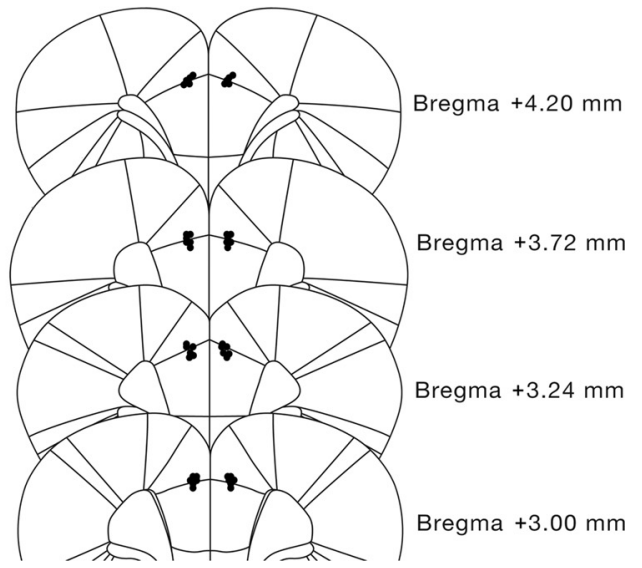

Figure 1. Schematic depiction of cannula placements in the PrL cortex in Experiments 1a, 1b, 2, and 3. Black dots indicate ventral point of the cannula tract. Animals with placements outside the area of interest were excluded.

microscope equipped with a CCD camera by using a $2 \times$ air objective. Exposure time was the same throughout the acquisition process. For integrated density of terminals in the pPVT, $z$ stacks $(\sim 20 \mu \mathrm{m})$ were captured with a Leica SP5 confocal microscope (10× air objective, $1024 \times 1024$ frame size, 12-bit resolution, 4 frame averages, $1.5 \mu \mathrm{m}$ step size). Settings (argon laser power $=31 \%$, scan speed $=400 \mathrm{~Hz}$, pinhole $=1.2$ airy units, offset $=-2.3 \%$, smart gain $=868.1$ ) were optimized initially and then held constant throughout the study to ensure that all images were digitized under the same illumination conditions. Images were imported into ImageJ and ROIs for anterior cingulate (Cg1), PrL and infralimbic (IL) cortices as well as pPVT were created and used similarly on all sections. The corrected integrated density (reported in figures as "Integrated Density") was calculated as integrated density of ROI-background value and averaged across 4 sections for each animal.

Experimental design and statistical analysis. All statistical analyses were performed using Stata MP14 (Stata). Lever presses for all cocaine and sucrose SA data were analyzed with a three-way mixed model ANOVA for repeated measures with the between-subjects factor, virus (eGFP or mCherry and hM4Di) and the within-subjects factor, lever (active and inactive) and session. In Experiments 1a, 2, and 3, active and inactive lever responses for the PA test and cue test were analyzed separately with a three-way mixed-factorial ANOVA with virus (eGFP or mCherry and $\mathrm{hM} 4 \mathrm{Di}$ ) and infusion (PBS and BDNF) as the between-subjects factors and the time point as within-subjects factor. Sidak pairwise comparison tests were performed when a significant interaction was observed. Active and inactive lever responses for the additional extinction sessions following the PA test were analyzed with a four-way repeated-measures ANOVA with virus (eGFP or mCherry and hM4Di) and infusion (PBS and BDNF) as between-subjects factor and lever (active and inactive) and session as the within-subjects factor. In Experiments $1 \mathrm{~b}$ and 4, active and inactive lever responses for the PA test and cue test were analyzed separately with a two-way mixed-factorial ANOVA with virus (eGFP or mCherry and hM4Di) as the between-subjects factor and time point as the within-subjects factor. Active and inactive lever responses for the 5 additional extinction sessions after the PA test were analyzed separately with a three-way mixed-factorial ANOVA with virus (eGFP or mCherry and hM4Di) as the between-subjects factor and lever (active and inactive) and session as the within-subjects factor. Because the multifactorial ANOVAs yielded multiple main and interaction effects, we only report significant effects that are critical for data interpretation. Statistical outliers were detected with a Grubbs test (when only one outlier was suspected) or with "R" Statistics software (R Core Team, Vienna, Austria) by running the Tietjen-Moore test and confirmed by the Rosner Test and Absolute Deviation Around the Median (when more than one outlier was suspected in a group). Cocaine-induced Fos-immunoreactivity (IR) data were analyzed with a two-tailed Student's $t$ test with Welch's correction. Correlation analyses were performed using a Pearson's correlation test. Statistical significance threshold was set at 0.05 , and all data are graphically represented as the mean \pm SEM.

\section{Results}

\section{Histology}

Schematic mapping of the cannulae placements for rats in Experiments $1-3$ is shown in Figure 1.

\section{Experiment 1: global chemogenetic inhibition of PrL projection neurons blocks BDNF-dependent, and drives a BDNF-independent, decrease in cocaine-seeking}

In Experiment 1a, 48 rats underwent surgery; 3 rats died from surgical complications or infection, 3 rats lost head caps, 4 were excluded due to missed cannula placements or lack of viral infection, and 2 were removed as statistical outliers for a final $N=36$. A schematic of the viral infusion and the experimental timeline is shown in Figure 2A. As shown in Figure 2B, viral expression was largely confined to the PrL cortex. Integrated density of hM4DimCherry-IR in the medial PFC revealed that $29.1 \%$ of the virus expression was in Cg1, 58.6\% in PrL, and $12.3 \%$ was in IL cortex. To validate the cell specificity of the infection, immunostaining was performed for $\alpha$ CaMKII and the hM4Di-mCherry tag. Colocalization analysis revealed that $86.4 \%$ of mCherry ${ }^{+}$neurons also expressed $\alpha$ CaMKII-IR (Fig. 2C). These results agree with a previous report that $\sim 80 \%$ of somatosensory cortical neurons infected in vivo with AAV- $\alpha$ CaMKII-driven constructs are excitatory neurons in layers V-VI of mice (Nathanson et al., 2009). Validation of DREADD activity revealed that hM4Di-mediated inhibition significantly decreased the number of cells expressing Fos-IR in the PrL cortex induced by a $10 \mathrm{mg} / \mathrm{kg}$, intraperitoneal injection of cocaine by $\sim 30 \%$ compared with eGFP control rats (eGFP vs hM4Di, $t_{(4)}=4.588, p=0.01$; Fig. $2 D$ ), and only $9 \%$ of Fos $^{+}$neurons were also hM4Di-mCherry ${ }^{+}$(eGFP vs Fos + mCherry, $t_{(4)}=15.17, p=0.006$; Fig. $2 D$ ). Rats learned to discriminate between the active and inactive levers quickly, and there were no differences in active or inactive lever pressing for cocaine between eGFP- and hM4D(Gi)-expressing rats over $14 \mathrm{~d}$ (session $\times$ lever interaction: $F_{(13,892)}=3.53, p<0.001$; session $\times$ virus $\times$ lever interaction: $F_{(13,892)}=1.06, p>0.05$; Figure $\left.2 E\right)$. Immediately after the last cocaine SA session, rats expressing either eGFP or hM4Di in the PrL cortex were injected with CNO $(10 \mathrm{mg} / \mathrm{kg}$, i.p.) followed $30 \mathrm{~min}$ later by a single intra-PrL microinfusion of either PBS or BDNF. After 1 week of home-cage 
A

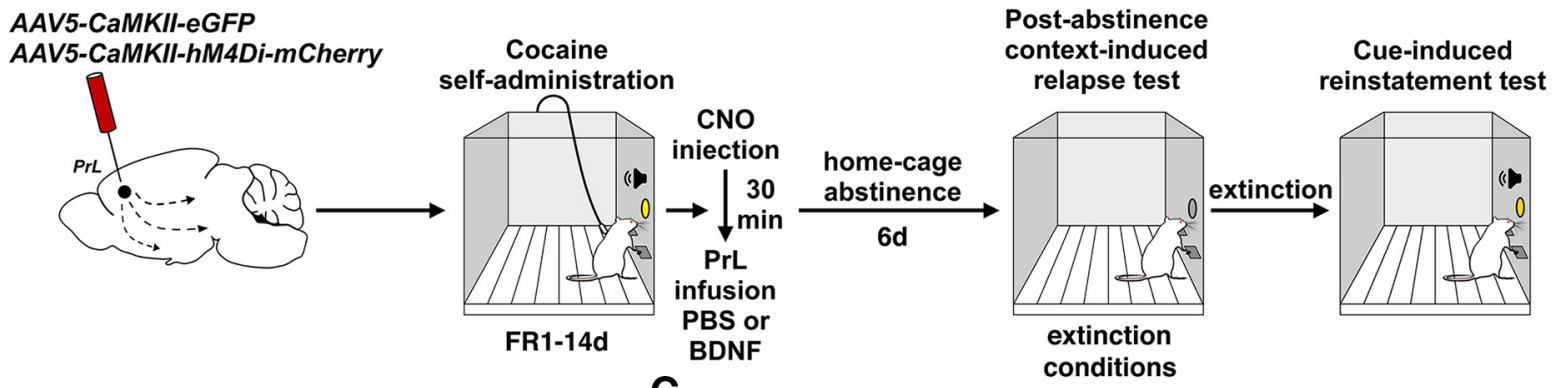

B
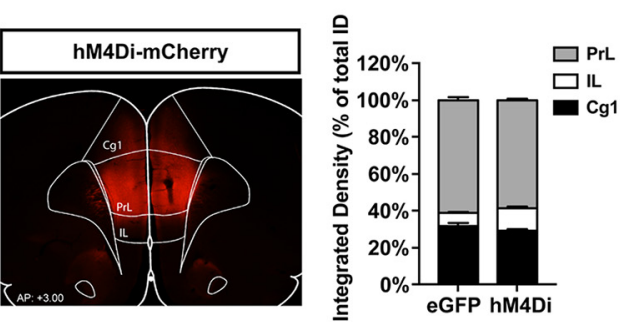

C

conditions
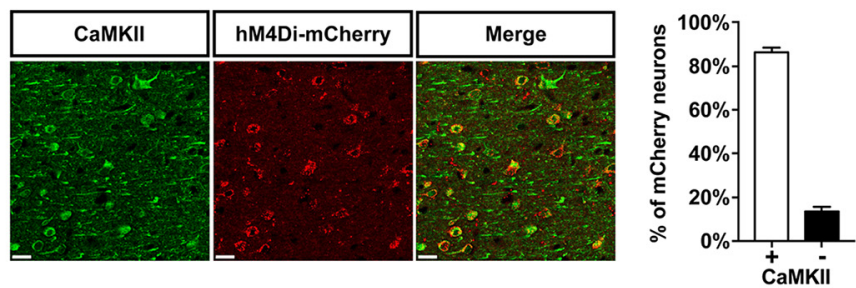

D

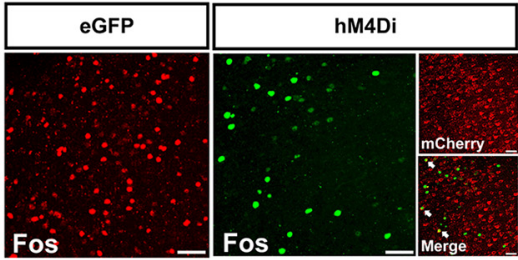

E

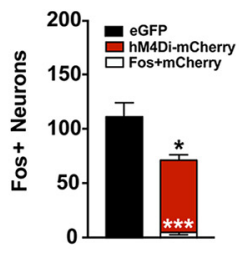

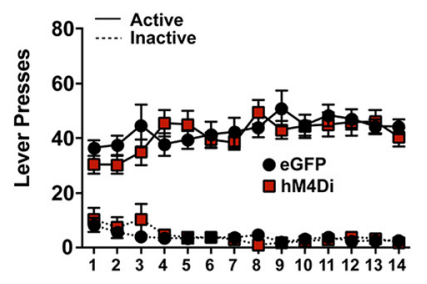
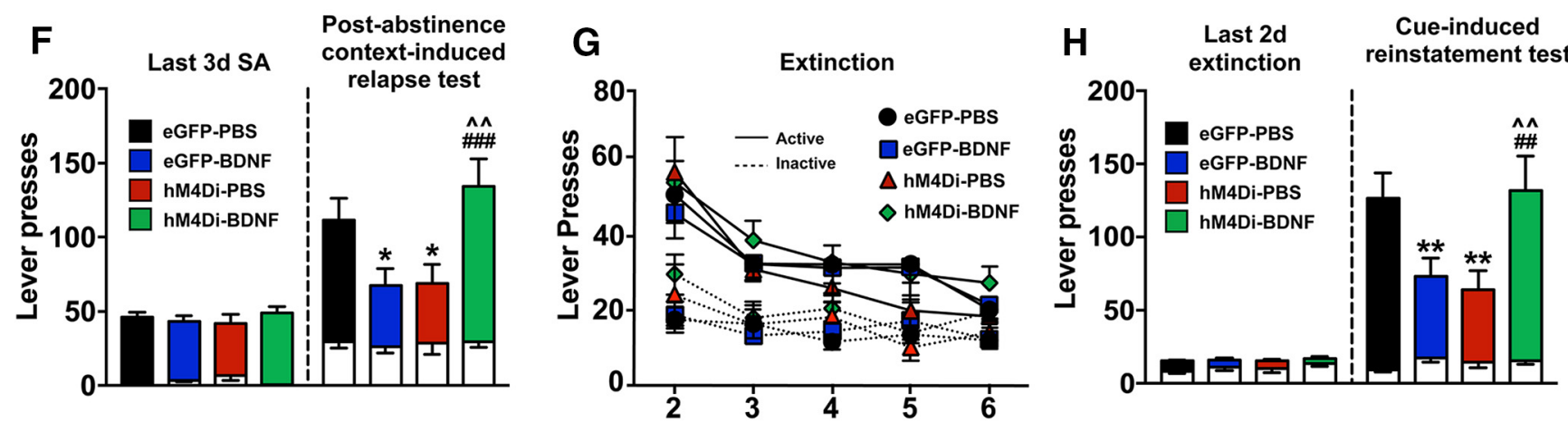

Figure 2. Chemogenetic inhibition of PrL excitatory neurons blocks BDNF-induced suppression of cocaine-seeking. $A$, Schematic illustration of the viral vector targeting approach and timeline for Experiment 1a. $\boldsymbol{B}$, Representative image showing the expression of $\alpha$ CaMKII-driven hM4Di-mCherry in PrL cortex and integrated density of viral spread within the medial PFC. $\boldsymbol{C}$, Validation of the cell-type specificity of the $\alpha$ CaMKII-hM4Di DREADD in $\alpha$ CaMKII ${ }^{+}$neurons and colocalization analysis. Scale bar, $20 \mu \mathrm{m}$. D. Validation of hM4Di functionality: activation of hM4Di attenuates acute cocaine-evoked Fos induction versus eGFP-expressing rats. ${ }^{*} p<0.05,{ }^{* * *} p<0.001$. White arrows indicate colocalization between hM4Di-mcherry and Fos. Scale bar, $40 \mu \mathrm{m}$. E, Acquisition and maintenance of cocaine SA. F, Post-abstinence context-induced relapse test. Left, Active (colored bars) and inactive (white bars) lever presses during the last $3 \mathrm{~d}$ of $S A$. Right, Active and inactive lever presses during the $2 \mathrm{~h}$ test. ${ }^{*} p<0.05$ versus eGFP-PBS. ${ }^{\# \# \#} p<0.001$ versus eGFP-BDNF. $\wedge \wedge p<0.01$ versus hM4Di-PBS. G, Following the PA test, rats extinguished lever pressing over an additional 5 sessions. $\boldsymbol{H}$, Cue-induced reinstatement test. Left, Active (colored bars) and inactive (white bars) lever presses during the last $2 \mathrm{~d}$ of extinction. Right, Active and inactive lever presses during the 2 h test. ${ }^{* *} p<0.01$ versus eGFP-PBS. ${ }^{\# \#} p<0.01$ versus eGFP-BDNF. $\wedge \wedge p=0.01$ versus $\mathrm{hM} 4 \mathrm{Di}-\mathrm{PBS}$.

abstinence, rats underwent a PA context-induced relapse test (PA test) under extinction conditions (Fig. 2F). Statistical analysis revealed a significant interaction between virus and intracranial infusion $\left(F_{(1,32)}=12.50, p=0.001\right)$ and a time point $\times$ virus $\times$ intracranial infusion interaction $\left(F_{(1,32)}=10.93, p=0.002\right)$. Sidak pairwise comparisons revealed that eGFP-expressing rats infused with PBS pressed the active lever significantly more during the PA test compared with the last 3 sessions of SA, indicating that a CNO injection in eGFP control rats did not affect their ability to relapse. As expected, a single intra-PrL infusion of BDNF decreased active lever pressing in eGFP-expressing rats and chemogenetic inhibition with hM4Di blocked the BDNF-mediated decrease (eGFP-BDNF vs eGFP-PBS: $p=0.0127$; hM4Di-BDNF vs eGFP-BDNF: $p=0.0002)$. Unexpectedly, however, hM4Dimediated inhibition decreased cocaine-seeking in PBS-infused rats, similar to the BDNF effect on cocaine-seeking (hM4Di-PBS vs eGFP-PBS: $p=0.0398$; hM4Di-BDNF vs hM4Di-PBS: $p=$ $0.0019)$. Following the PA test, rats extinguished lever pressing over an additional 5 extinction sessions, and there were no differences in the rate of extinction between experimental groups (session: $F_{(4,288)}=25.82, p<0.001$; session $\times$ lever interaction: $F_{(4,288)}=7.81, p<0.001$; session $\times$ virus $\times$ infusion $\times$ lever interaction: $F_{(4,288)}=0.19, p>0.05$; Figure $\left.2 G\right)$. Following extinction, rats underwent a cue test (Fig. $2 H$ ). Statistical analysis revealed a virus $\times$ intracranial infusion interaction $\left(F_{(1,32)}=\right.$ $10.67, p=0.002)$ and a time point $\times$ virus $\times$ intracranial infu- 
A

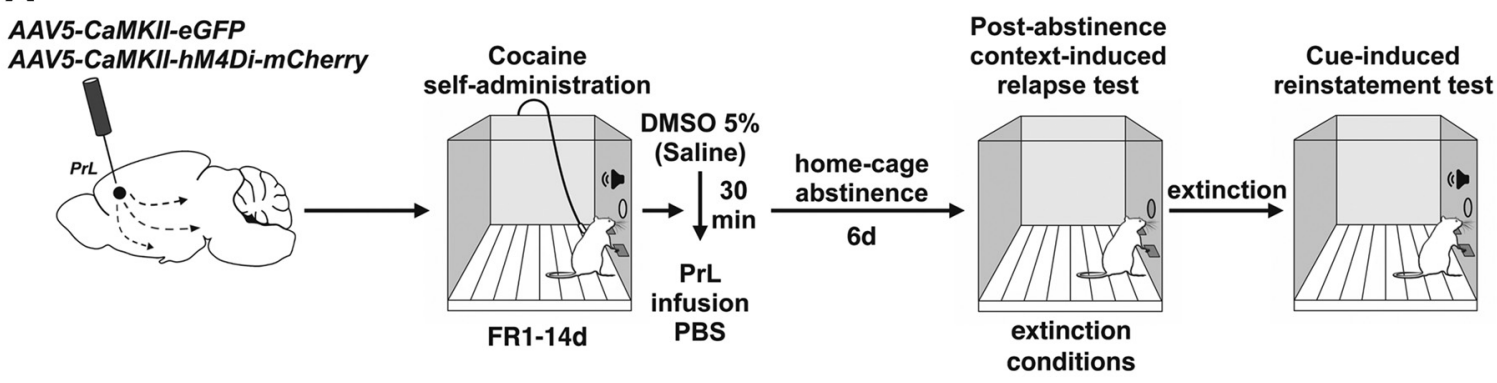

B

Cocaine self-administration

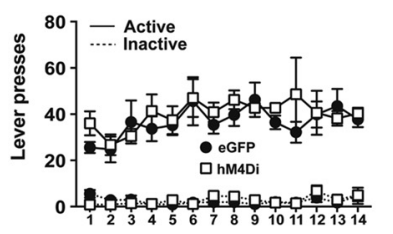

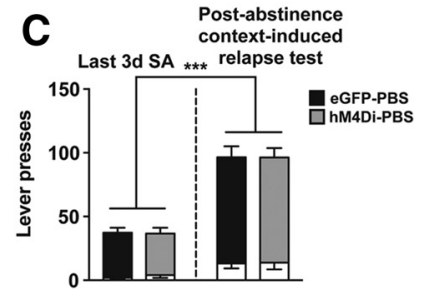
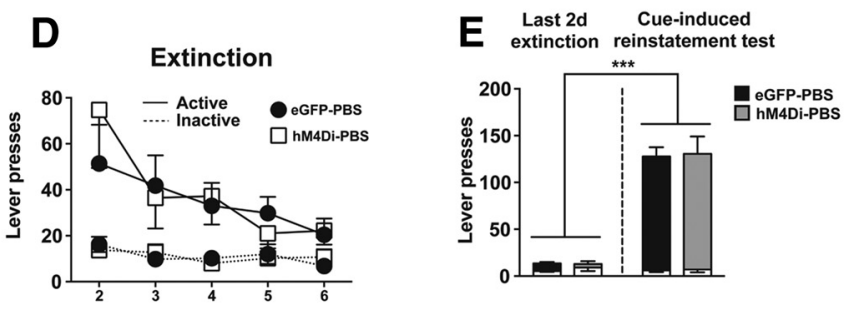

Figure 3. $\alpha$ CaMKII-driven hM4Di-mediated attenuation of cocaine-seeking requires CNO-mediated activation of hM4Di DREADD. $A$, Schematic illustration of the viral vector targeting approach and timeline for Experiment 1b. B, Acquisition and maintenance of cocaine SA. C, Post-abstinence context-induced relapse test. Left, Active and inactive (white bars) lever presses during the last $3 \mathrm{~d}$ of SA. Right, Active (colored bars) and inactive (white bars) lever presses during the $2 \mathrm{~h}$ test. ${ }^{* * *} p<0.001$ versus last $3 \mathrm{~d}$ of SA. D, Following the PA test, rats extinguished lever pressing over an additional 5 sessions. $\boldsymbol{E}$, Cue-induced reinstatement test. Left, Active (colored bars) and inactive (white bars) lever presses during the last $2 \mathrm{~d}$ of extinction. Right, Active and inactive lever presses during $2 \mathrm{~h}$ test. ${ }^{* *} p<0.001$ versus last $2 \mathrm{~d}$ of extinction.

sion interaction $\left(F_{(1,32)}=10.96, p=0.002\right)$. eGFP control rats pressed the active lever significantly more during the cue test compared with the last $2 \mathrm{~d}$ of extinction. As expected, infusion of BDNF decreased active lever responses in eGFP-expressing rats, and chemogenetic inhibition of PrL neurons blocked this effect (eGFP-BDNF vs eGFP-PBS: $p=0.0078$; hM4Di-BDNF vs eGFPBDNF: $p=0.0067)$. However, as observed in the PA test, chemogenetic inhibition significantly decreased active lever pressing during the cue test in PBS-infused rats (hM4Di-PBS vs eGFPPBS: $p=0.007$; hM4Di-BDNF vs hM4Di-PBS: $p=0.006$ ).

A previous study showed that expression of a hM4DiDREADD in sensory neurons caused CNO-independent changes in $\mathrm{Ca}^{2+}$ and $\mathrm{Na}^{+}$currents (Saloman et al., 2016). Accordingly, we conducted a control experiment (Experiment $1 \mathrm{~b}$ ) in the absence of CNO (Fig. 3A). Rats learn to discriminate between the active and inactive levers quickly, and there were no differences between eGFP- and hM4Di-expressing rats (session: $F_{(13,189)}=$ $1.82, p=0.0423$; session $\times$ lever interaction: $F_{(13,189)}=1.81, p=$ 0.0440 ; session $\times$ virus $\times$ lever interaction: $F_{(13,189)}=0.74, p>$ 0.05 ; Figure $3 B$ ). When rats were injected with $5 \%$ DMSO vehicle followed by an intra-PrL PBS microinfusion immediately after the last cocaine SA session, there was no difference in active lever pressing between groups expressing eGFP and hM4Di during the PA test (Fig. 3C). Following the PA test, rats extinguished lever pressing over an additional 5 extinction sessions, and there were no differences in the rate of extinction between experimental groups (session: $F_{(4,63)}=6.01, p<0.001$; session $\times$ lever interaction: $F_{(4,63)}=3.54, p=0.0114$; virus $\times$ session $\times$ lever interaction: $F_{(4,63)}=0.86, p>0.05$; Figure $\left.3 D\right)$. Following extinction, rats underwent a cue test (Fig. $3 E$ ), and there was no difference in active lever pressing between groups.

Experiment 2: selective inhibition of $\mathrm{PrL}$ neurons projecting to NAc core blocks BDNF-induced decrease in cocaine-seeking

A schematic of the viral infusion and the experimental timeline are depicted in Figure 4A. Thirty-two rats underwent surgery: 1 rat died from intracranial surgical complications, 4 rats were removed due to lack of viral expression or missed target, and 1 rat was a statistical outlier (final $N=26$ ). Cre-dependent hM4Di expression was verified by mCherry-IR in PrL neurons and in NAc core terminals, and the CAV2-Cre injection site was verified via eGFP-IR (Fig. 4B). Rats acquired and maintained cocaine SA over $14 \mathrm{~d}$, and there were no differences between mCherry- and hM4Di-expressing rats (session $\times$ lever interaction: $F_{(13,629)}=$ 2.52, $p=0.0023$; session $\times$ virus $\times$ lever interaction: $F_{(13,629)}=$ $1.24, p>0.05$; Figure $4 C$ ). Immediately after the last cocaine session, mCherry controls and hM4Di-expressing rats were injected with $\mathrm{CNO}(10 \mathrm{mg} / \mathrm{kg}$, i.p.) and infused with PBS or BDNF in the PrL cortex 30 min later. After 1 week of abstinence, the rats underwent a PA test (Fig. 4D). Statistical analysis of active lever presses revealed a virus $X$ intracranial infusion interaction $\left(F_{(1,22)}=7.31, p=0.013\right)$ and an interaction between time point, virus, and intracranial infusion $\left(F_{(1.22)}=4.50, p=0.045\right)$. Sidak pairwise comparisons revealed that mCherry rats infused with PBS pressed the active lever significantly more during the PA test compared with the last 3 sessions of SA, indicating that $\mathrm{CNO}$ injection in mCherry control rats did not prevent relapse. As expected, infusion of BDNF decreased relapse in mCherryexpressing rats and chemogenetic inhibition of PrL-NAc core neurons blocked BDNF's inhibitory effect on cocaine-seeking (mCherry-BDNF vs mCherry-PBS: $p=0.015$; hM4Di-BDNF vs mCherry-BDNF: $p=0.0025)$. In contrast to the decrease in cocaine-seeking after $\alpha$ CaMKII-driven chemogenetic inhibition of PrL neurons in Experiment 1a, inhibition of PrL-NAc core neurons did not decrease relapse in the absence of BDNF. Rats extinguished lever pressing over an additional 5 extinction sessions following the PA test; there were no differences in the rate of extinction on these days between experimental groups (session: $F_{(4,198)}=15.63, p<0.001$; session $\times$ lever interaction: $F_{(4,198)}=$ $4.55, p=0.0016$; session $\times$ virus $\times$ infusion $\times$ lever interaction: $F_{(4,198)}=0.28, p>0.05$; Figure $\left.4 E\right)$. Following extinction, rats underwent a cue test (Fig. $4 F$ ). Statistical analysis of active lever presses revealed a significant time point $X$ virus $X$ intracranial 
A

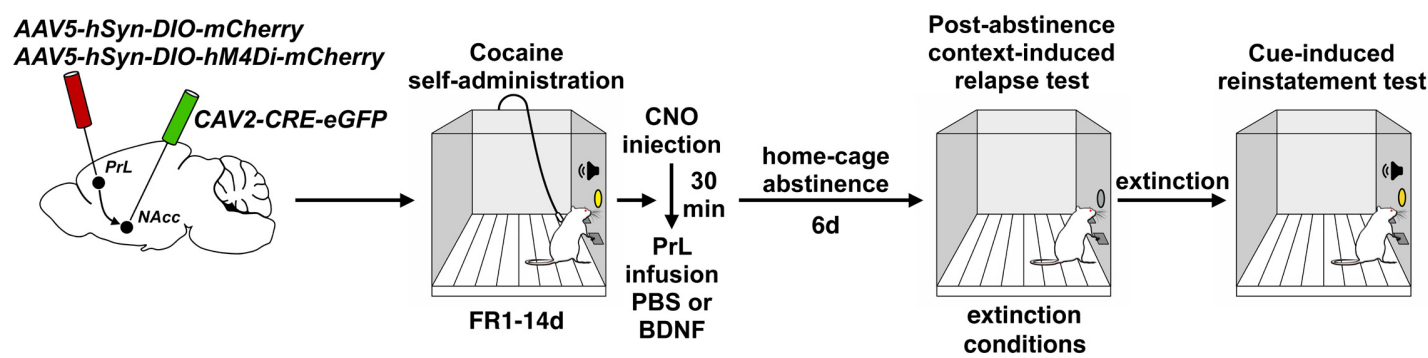

B

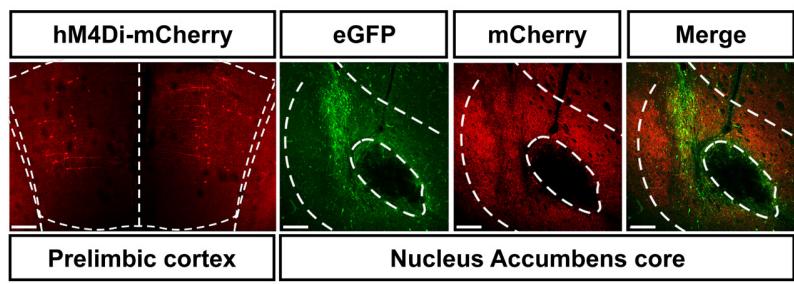

C
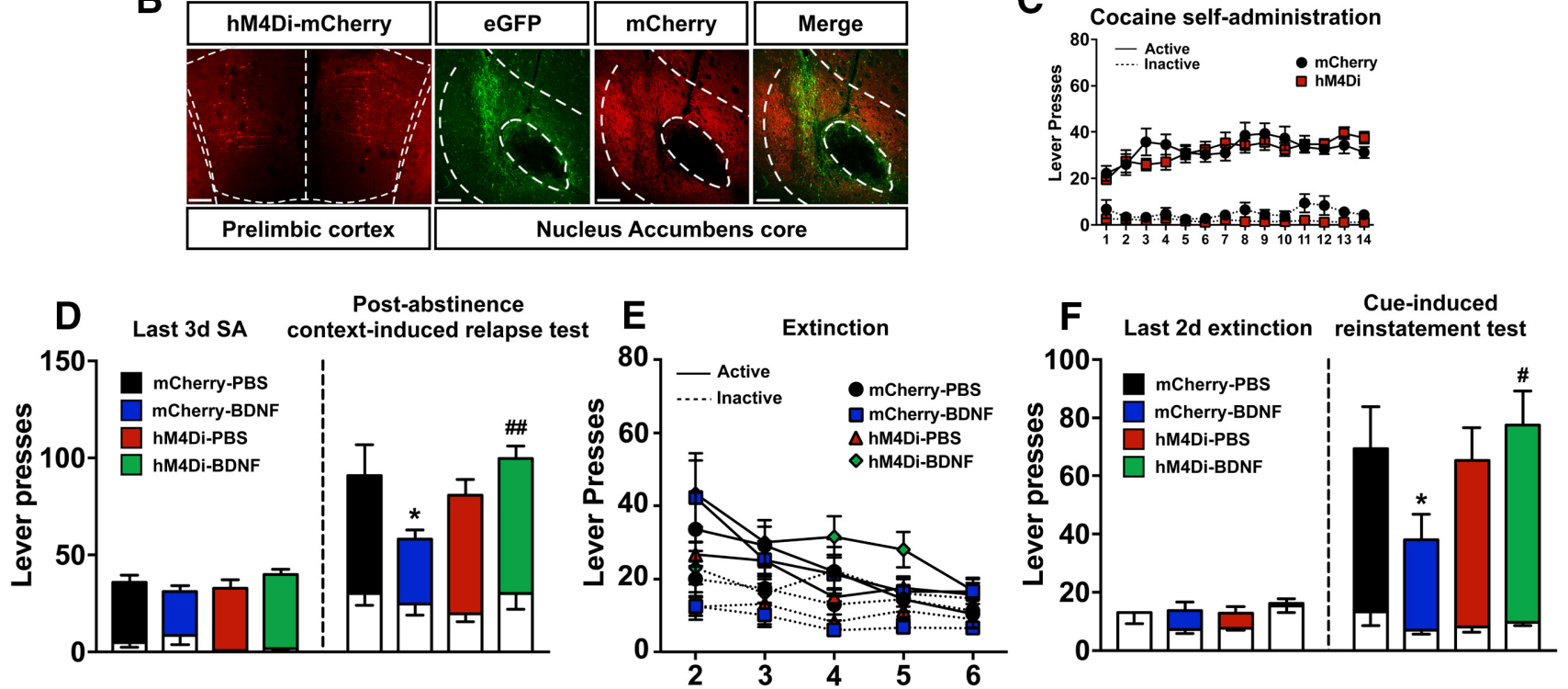

Figure 4. Inhibition of PrL neurons projecting to NAc core selectively blocked BDNF-dependent effects on cocaine-seeking. $A$, Schematic illustration of the viral vector targeting approach and timeline for Experiment 2. B, Representative images of hM4Di-mCherry expression in PrL cortex, as well as CAV-2-Cre-eGFP- and hM4Di-mCherry-expressing terminals in NAc core. Scale bar, 150 $\mu \mathrm{m}$. C, Acquisition and maintenance of cocaine SA. D, Post-abstinence context-induced relapse test. Left, Active (colored bars) and inactive (white bars) lever presses during the last $3 \mathrm{~d}$ of SA. Right, Active and inactive lever presses during $2 \mathrm{~h}$ test. ${ }^{*} p<0.05$ versus mCherry-PBS. ${ }^{\# \#} p<0.01$ versus mCherry-BDNF. $E$, Following the PA test, rats extinguished lever pressing over an additional 5 sessions. $\boldsymbol{F}$, Cue-induced reinstatement test. Left, Active (colored bars) and inactive (white bars) lever presses during the last $2 \mathrm{~d}$ of extinction. Right, Active and inactive (white bars) lever presses during $2 \mathrm{~h}$ test. ${ }^{*} p<0.05$ versus mCherry-PBS. ${ }^{\#} p<0.05$ versus mCherry-BDNF.

infusion interaction $\left(F_{(1,22)}=4.53, p=0.044\right)$. Control mCherry rats infused with PBS pressed the active lever significantly more during the cue test compared with the last $2 \mathrm{~d}$ of extinction. As expected, mCherry-expressing rats infused with BDNF pressed the active lever significantly less than PBS-infused rats during the cue test and chemogenetic inhibition of PrL-NAc core neurons blocked BDNF's inhibitory effect on cocaine-seeking in this test (mCherry-BDNF vs mCherry-PBS: $p=0.045$; hM4Di-BDNF vs mCherry-BDNF: $p=0.011)$. As in the PA test, inhibition of PrL-NAc core neurons did not decrease reinstatement during the cue test in the absence of BDNF.

Experiment 3: selective inhibition of PrL neurons projecting to pPVT decreases cocaine-seeking

To identify a neuronal pathway that mediates hM4Di-induced decreases in cocaine-seeking in PBS-infused rats as observed in Experiment 1a, we investigated terminal expression in brain regions receiving projections from the PrL cortex (Gabbott et al., 2005 ) in those rats. In the hM4Di-expressing rats, there was dense terminal expression in thalamic nuclei and, in particular, in the posterior aspect of the PVT. Interestingly, analyses of the integrated density of pPVT terminal expression showed a negative correlation with the amount of active lever presses during both the PA $\left(r^{2}=0.7584, p=0.0239\right.$; Fig. $\left.5 A\right)$ and the cue test $\left(r^{2}=\right.$ $0.8565, p=0.008$; Fig. $5 B$ ) in Experiment 1a. Moreover, $2 \mathrm{~h}$ after the last cocaine SA session, we found an increase in Fos-IR in the $\operatorname{pPVT}\left(t_{(7)}=5.147, p=0.0028\right.$, unpaired $t$ test with Welch's correction; Fig. $5 C$, top) and in layer VI of the PrL cortex $\left(t_{(7)}=\right.$ 2.783, $p=0.0376$, unpaired $t$ test with Welch's correction; Fig. $5 C$, bottom), indicating that both PrL cortical neurons in layer VI and the pPVT are activated during early withdrawal. These data suggested that chemogenetic inhibition of PrL-pPVT neurons may suppress cocaine-seeking. A schematic of the viral infusion and the timeline for this experiment are depicted in Figure 5D. Cre-dependent hM4Di expression in PrL neurons and in PVT terminals was verified by mCherry-IR, and the AAVrg-Cre injection site was verified via BFP-IR (Fig. $5 E$ ). We verified the spread of the AAVrg infusion by counting the number of $\mathrm{BFP}^{+}$profiles across the anterior-posterior axis of the PVT, and we found that virus infusion was confined to the pPVT (Fig. $5 F$ ). Forty-eight rats underwent surgery: 5 rats were removed due to lack of viral expression, 1 due to a failed catheter, 3 rats lost head caps, 1 rat died from surgical complications (final $N=38$ ). Rats learned to discriminate between the active and inactive levers quickly, and there were no differences between mCherry- and hM4Diexpressing rats (session: $F_{(13,855)}=2.12, p=0.0115$; session $\times$ lever interaction: $F_{(13,855)}=2.85, p<0.001$; session $\times$ virus $\times$ lever interaction: $F_{(13,855)}=0.65, p>0.05$; Fig. $\left.5 G\right)$. Immediately after the last cocaine session, mCherry controls and hM4Diexpressing rats were injected with $\mathrm{CNO}(10 \mathrm{mg} / \mathrm{kg}$, i.p. $)$ and in- 
A

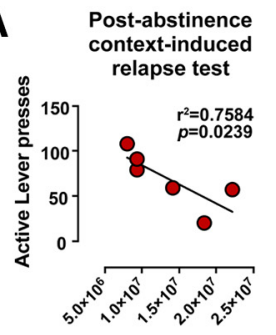

Integrated Density PVT
B

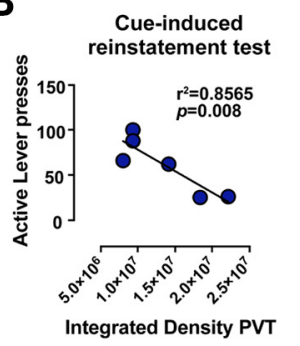

C

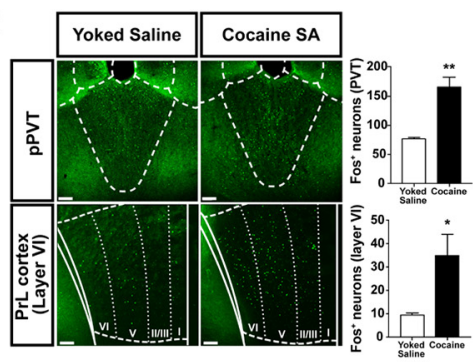

D

AAV5-hSyn-DIO-mCherry AAV5-hSyn-DIO-hM4Di-mCherry

Cocaine self-administration

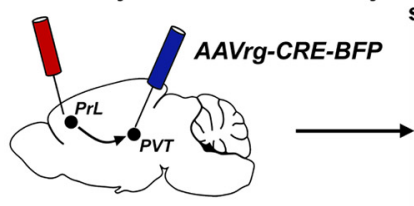

E

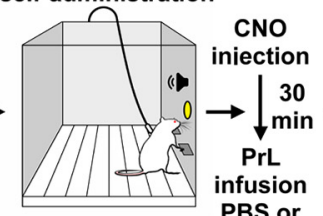

FR1-14d BDNF

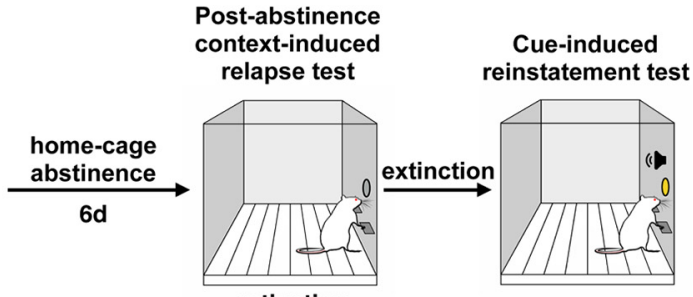

extinction conditions

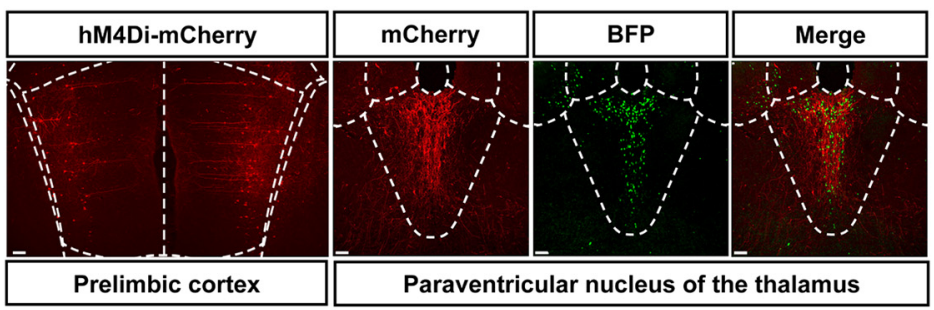

$F$

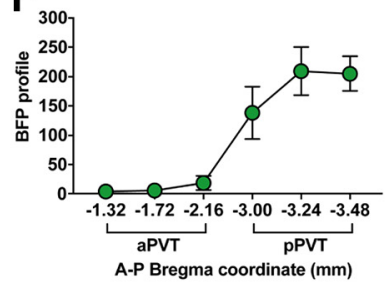

A-P Bregma coordinate $(\mathrm{mm})$

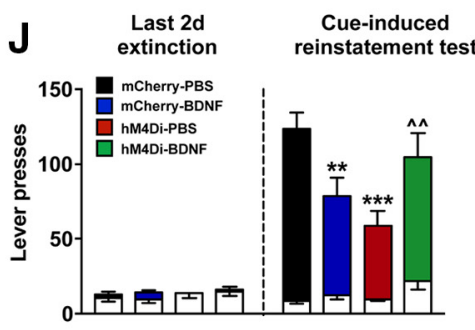

Figure 5. Inhibition of PrL neurons projecting to pPVT suppresses cocaine-seeking. Correlation between $\alpha$ CaMKII-driven hM4Di-expressing terminals in pPVT and active lever presses during PA $(\boldsymbol{A})$ and cue test $(\boldsymbol{B})$ of rats in Experiment 1a. C, Early withdrawal $(2 \mathrm{~h})$ from the last cocaine SA session induces Fos-IR in pPVT and in layer VI of PrL cortex. ${ }^{*} p<0.05$ versus yoked-saline. ${ }^{* *} p<0.01$ versus yoked-saline. Scale bar, $150 \mu \mathrm{m}$. D, Schematic illustration of the viral vector targeting approach and timeline for Experiment $3 . E$, Representative images of hM4Di-mCherry expression in PrL cortex, as well as AAVrg-CRE-BFP and hM4Di-mCherry-expressing terminals in pPVT. Scale bar, $150 \mu \mathrm{m}$. $\boldsymbol{F}$, BFP profiles across the anterior-posterior axis of PVT. G, Acquisition and maintenance of cocaine SA. $\boldsymbol{H}$, Post-abstinence context-induced relapse test. Left, Active (colored bars) and inactive (white bars) lever presses during the last $3 \mathrm{~d}$ of cocaine SA. Right, Active and inactive lever presses during the $2 \mathrm{~h}$ test. ${ }^{* *} p<0.01$ versus mCherry-PBS. ${ }^{* * *} p<0.001$ versus mCherry-PBS. ${ }^{\# \#} p<0.01$ versus mCherry-BDNF. $\wedge \wedge \wedge p<0.001$ versus $\mathrm{hM4Di-PBS.} I$, Following the PA test, rats extinguished lever pressing over an additional 5 sessions.J, Cue-induced reinstatement test. Left, Active (colored bars) and inactive (white bars) lever presses during the last $2 \mathrm{~d}$ of extinction. Right, Active and inactive lever presses during the $2 \mathrm{~h}$ test. ${ }^{* *} p<0.01$ versus $\mathrm{mCherry}-\mathrm{PBS} .{ }^{* * *} p<0.0001$ versus $\mathrm{mCherry}-\mathrm{PBS} . \wedge \wedge p<0.01$ versus hM4Di-PBS.

fused with PBS or BDNF in the PrL cortex 30 min later. After 1 week of abstinence, the rats underwent a PA test (Fig. $5 \mathrm{H}$ ). Statistical analysis of active lever presses revealed a virus $X$ intracranial infusion interaction $\left(F_{(1,34)}=19.62, p=0.0001\right)$ and an interaction between time point, virus, and intracranial infusion $\left(F_{(1,34)}=9.02, p=0.005\right)$. Sidak pairwise comparisons revealed that mCherry-control rats infused with PBS pressed the active lever significantly more during the PA test compared with the last 3 sessions of $\mathrm{SA}$, indicating that $\mathrm{CNO}$ injection in mCherry control rats did not prevent relapse. Again, infusion of BDNF decreased relapse in mCherry-expressing rats (mCherry-BDNF vs mCherry-PBS: $p=0.0017$ ). As hypothesized, chemogenetic inhibition of PrL-pPVT neurons immediately after the last cocaine SA session decreased relapse in PBS-infused rats but not in BDNF-infused rats (hM4Di-PBS vs mCherry-PBS: $p=0.0001$; hM4Di-BDNF vs mCherry-BDNF: $p=0.0016$; hM4Di-BDNF vs
hM4Di-PBS: $p=0.00016)$. Rats extinguished lever pressing over an additional 5 extinction sessions following the PA test; there were no differences in the rate of extinction on these days between experimental groups (session: $F_{(4,306)}=33.79, p<0.001$; session $\times$ lever interaction: $F_{(4,306)}=6.96, p<0.001$; session $\times$ virus $X$ infusion $\times$ lever interaction: $F_{(4,306)}=0.90, p>0.05$; Figure $5 I$ ). After extinction to criterion, rats underwent a cue test (Fig. 5J). Statistical analysis of active lever presses revealed a virus $X$ intracranial infusion interaction $\left(F_{(1,34)}=10.14, p=\right.$ $0.0031)$ and an interaction between time point, virus, and intracranial infusion $\left(F_{(1,34)}=11.50, p=0.0018\right)$. Sidak pairwise comparisons revealed that mCherry rats infused with PBS pressed the active lever significantly more during the cue test compared with the last $2 \mathrm{~d}$ of extinction. Consistent with findings on the PA test, infusion of BDNF decreased active lever responses in mCherry control animals, and chemogenetic inhibition of 
A

AAV5-hSyn-DIO-mCherry AAV5-hSyn-DIO-hM4Di-mCherry
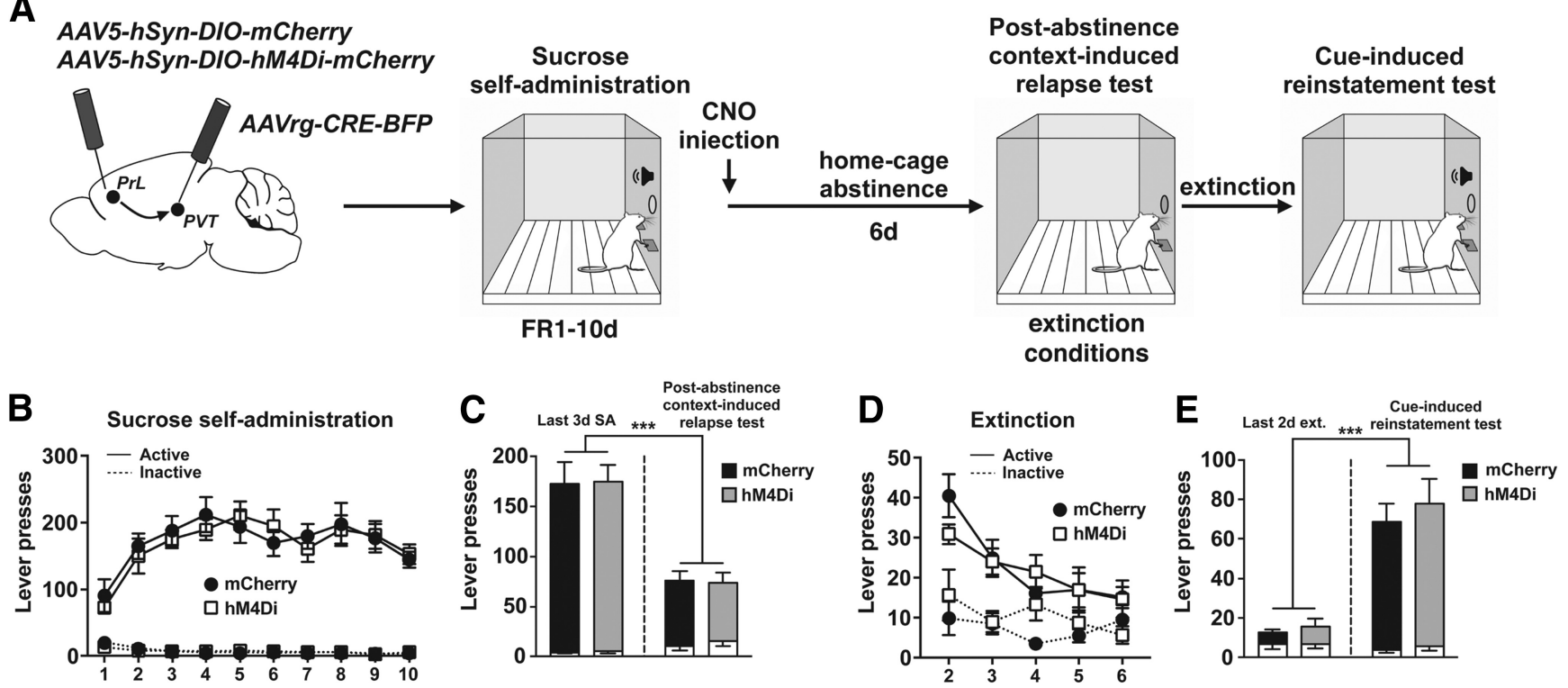

Figure 6. Inhibition of PrL-pPVT neurons did not alter sucrose-seeking. A, Schematic illustration of the viral vector targeting approach and timeline for Experiment 4. B, Acquisition and maintenance of sucrose SA. C, Post-abstinence context-induced relapse test. Left, Active (colored bars) and inactive (white bars) lever presses during the last $3 \mathrm{~d}$ of sucrose SA. Right, Active and inactive lever presses during the $2 \mathrm{~h}$ test. ${ }^{* * *} p<0.001$ versus last $3 \mathrm{~d}$ of $S A$. D, Following the PA test, rats extinguished lever pressing over an additional 5 sessions. $\boldsymbol{E}$, Cue-induced reinstatement test. Left, Active (colored bars) and inactive (white bars) lever presses during the last $2 \mathrm{~d}$ of extinction. Right, Active and inactive lever presses during the $2 \mathrm{~h}$ test. ${ }^{* * *} p<0.001$ versus last $2 \mathrm{~d}$ of extinction.

PrL-pPVT neurons decreased relapse and prevented BDNF's inhibitory effect on relapse (mCherry-BDNF vs mCherry-PBS: $p=$ 0.0024; hM4Di-PBS vs mCherry-PBS: $p<0.0001$; hM4Di-BDNF vs hM4Di-PBS: $p=0.0024$ ).

\section{Experiment 4: selective inhibition of PrL neurons projecting to PVT did not alter sucrose-seeking}

To investigate whether the suppression of cocaine-seeking mediated by the inhibition of PrL-pPVT neurons immediately after the last cocaine SA session was specific for cocaine versus a natural reward, rats $(N=16)$ underwent $10 \mathrm{~d}$ of sucrose SA. Schematic of the viral infusion and the timeline for Experiment 4 are depicted in Figure 6A. Viral spread was confined to the PrL cortex and pPVT as in Experiment 3 (data not shown). Rats acquire and maintain sucrose SA over $10 \mathrm{~d}$, and there were no differences between mCherry- and hM4Di-expressing animals (session: $F_{(9,256)}=5.23, p<0.001$; session $\times$ lever interaction: $F_{(9,256)}=$ $6.89, p<0.001$; session $\times$ virus $\times$ lever interaction: $F_{(9,256)}=$ $0.39, p>0.05$; Figure $6 B$ ). Immediately after the last sucrose SA session, all the rats were injected with $\mathrm{CNO}(10 \mathrm{mg} / \mathrm{kg}$, i.p. $)$ and then underwent 1 week of home cage abstinence followed by a PA test (Fig. 6C). Analysis of active lever responses revealed only a main effect of time point $\left(F_{(1,14)}=94.04, p<0.001\right)$ and no difference between the experimental groups (virus $\times$ time point interaction: $\left.F_{(1,14)}=0.033, p>0.05\right)$. Rats extinguished lever pressing over an additional 5 extinction sessions following the PA test; there were no differences in the rate of extinction on these days between experimental groups (session: $F_{(4,126)}=12.40, p<$ 0.001 ; session $\times$ lever interaction: $F_{(4,126)}=4.31, p=0.0026$; session $X$ virus $\times$ lever interaction: $F_{(4,126)}=1.33, p>0.05$; Figure $6 D$ ). Following extinction, rats underwent a cue test (Fig. $6 E)$. ANOVA revealed a main effect of time point $\left(F_{(1,14)}=72.73\right.$, $p<0.001)$ with no difference between mCherry controls and hM4Di-inhibition groups (virus $\times$ time point interaction: $F_{(1,14)}=$ $0.217, p>0.05)$.

\section{Discussion}

In this study, we demonstrated that chemogenetic inhibition of PrL projection neurons using a $\alpha$ CaMKII-driven hM4Di immediately after the last cocaine SA session blocked the ability of an intra-PrL BDNF infusion to decrease subsequent cocaineseeking. This finding confirms our previous pharmacological study that BDNF's inhibitory effects on cocaine-seeking require synaptic activity in PrL neurons (Go et al., 2016) and extends it to $\alpha$ CaMKII-expressing, putative pyramidal neurons. However, the unexpected finding that the $\alpha$ CaMKII-driven hM4Di-DREADD also decreased relapse in the absence of BDNF led us to consider the projection specificity of different PrL outputs in these effects. Thus, using a combinatorial viral vector approach, we found that selectively inhibiting the neuronal activity of PrL-NAc core pathway immediately after the end of cocaine SA blocked BDNF's effects on cocaine-seeking without having any effect in PBSinfused rats. Thus, it was necessary to identify the pathway mediating the $\alpha$ CaMKII-driven hM4Di-mediated decrease in cocaine-seeking that occurred in the absence of BDNF. Based on recent literature suggesting the PrL-pPVT projection opposes the PrL-NAc core projection (James and Dayas, 2013; Otis et al., 2017), we selectively inhibited the PrL-pPVT pathway. Using a similar retro-DREADD approach (Tervo et al., 2016), we found that inhibition of the PrL-pPVT neurons immediately after the last cocaine SA session was sufficient to decrease subsequent cocaine-seeking without altering sucrose-seeking in a similar paradigm. Because recent studies have shown that CNO administration in the absence of hM4Di or hM3Dq expression has behavioral effects in rats (MacLaren et al., 2016), possibly mediated by conversion of CNO to its active metabolite, clozapine (Gomez et al., 2017), we demonstrated that a single injection of CNO immediately after the last cocaine SA session did not alter relapse in eGFP- or mCherry-control rats. 


\section{Global inhibition of activity in $\operatorname{PrL} \alpha \mathrm{CaMKII}^{+}$neurons causes a BDNF-dependent and independent decrease in cocaine-seeking}

Chemogenetic inhibition of $\alpha$ CaMKII-expressing PrL neurons prevented the ability of exogenous BDNF to decrease cocaineseeking, indicating that synaptic activity in these neurons is necessary for BDNF's effects. We hypothesized that hM4Di inhibition by itself during early withdrawal would not affect cocaineseeking because (1) activity in the majority of neurons in deep layers of PrL cortex is downregulated during cocaine SA (Dennis et al., 2018); (2) cocaine SA causes profound dephosphorylation of GluN2A, GluN2B, ERK, and CREB in PrL cortex that is prevented by BDNF; and (3) GluN antagonists, TrkB, or ERK inhibitors infused immediately after the end of cocaine SA by themselves do not affect subsequent cocaine-seeking but prevent the effects of BDNF (Whitfield et al., 2011; Go et al., 2016). Possible differences in the actions of the pharmacological inhibitors versus $\alpha$ CaMKII promoter-driven hM4Di-induced inhibition are that the former bind to NMDA receptors on pyramidal and nonpyramidal (GABAergic) cells, whereas $\alpha$ CaMKII infection has a transcriptional bias toward infecting cortical excitatory neurons (Nathanson et al., 2009).

Inhibition of synaptic activity selectively in PrL-NAc neurons prevents the BDNF-induced decrease in cocaine-seeking

Based on studies indicating the importance of the PrL-NAc core pathway in cocaine-seeking (McFarland and Kalivas, 2001; Stefanik et al., 2016) and the ability of exogenous BDNF infused immediately after the end of cocaine SA to normalize extracellular glutamate levels in the NAc core (Berglind et al., 2009), we confirmed that selective inhibition of the PrL-NAc core pathway is sufficient to block BDNF-mediated reduction of cocaineseeking. These data indicate that BDNF's suppressive effects on cocaine-seeking are not only activity-dependent, but PrL-NAc core pathway-specific. Cocaine SA causes a selective deficit in PrL-NAc core neuronal responsiveness indicated by less nuclear Fos-IR and pCREB-IR and less AMPA receptor localization in large spine heads of PrL-NAc core neurons than in yoked-saline rats during early cocaine withdrawal (B. M. Siemsen et al., unpublished observations). We hypothesize that BDNF prevents these cocaineinduced deficits in PrL-NAc neurons, thereby enhancing excitatory synaptic strength as has been shown in other brain circuits (Kafitz et al., 1999; He et al., 2005; Leal et al., 2015, 2017; Kowianski et al., 2018)

\section{Inactivation of PrL neurons projecting to PVT immediately} after the last cocaine SA decreases cocaine-seeking

The ability of global chemogenetic inhibition of PrL neurons to decrease cocaine-seeking was equal in magnitude to that observed with intra-PrL BDNF infusion. We confirmed that the BDNF-independent decrease in relapse was mediated by $\mathrm{CNO}$ because vehicle-treated rats that expressed hM4Di did not demonstrate this effect. Moreover, when hM4Di was selectively expressed in PrL-NAc neurons, CNO did not decrease cocaine-seeking in PBSinfused rats, ruling out the contribution of this pathway to the BDNF-independent decrease in cocaine-seeking observed after global chemogenetic inhibition of PrL projection neurons.

The PrL cortex has projections to many subcortical brain regions mediating motivated behaviors, including the PVT (Li and Kirouac, 2012; James and Dayas, 2013; Millan et al., 2017). We found dense terminal expression in the pPVT of the $\alpha$ CaMKIIdriven hM4Di-expressing rats and found that the integrated density of these terminals negatively correlated with cocaine-seeking, raising the possibility that the PrL-pPVT pathway might mediate the BDNF-independent suppression of cocaine-seeking after global chemogenetic inhibition of PrL projection neurons. Moreover, we found that Fos-IR was increased in layer VI of the PrL cortex and the pPVT of rats $2 \mathrm{~h}$ after the last cocaine SA session, further suggesting that the PrL-pPVT pathway is activated during early withdrawal. PrL-PVT neurons that are located in layer VI of the PrL cortex have recently been shown to play a critical role in reward learning (Millan et al., 2017; Otis et al., 2017). Further, inactivation of the PVT abolished the expression of cocaineconditioned place preference (Browning et al., 2014), attenuated cocaine-induced locomotor sensitization (Young and Deutch, 1998), as well as cue- and cocaine prime-induced reinstatement (James et al., 2010; Martin-Fardon and Boutrel, 2012; James and Dayas, 2013; Matzeu et al., 2015, 2017; Kuhn et al., 2018). Moreover, excitotoxic lesions of the PVT attenuated context-induced reinstatement of alcohol-seeking (Hamlin et al., 2009). More recently, it has been shown that structurally segregated PrL neurons projecting either to the NAc or PVT are activated differentially in response to reward-associated cue stimuli (Otis et al., 2017). Although most of the literature about the contribution of PVT in motivated behaviors does not differentiate between the anterior versus posterior divisions, recently the anterior PVT has been associated with sucroseseeking (Do-Monte et al., 2017), whereas the pPVT regulates relapse to drug-seeking (Matzeu et al., 2015). Accordingly, we found that inhibition of the PrL-pPVT pathway immediately after the last cocaine SA session decreases cocaine, but not sucrose, seeking in both the PA and cue tests. To the best of our knowledge, these data are the first to show that chemogenetic inhibition of the PrL-pPVT pathway immediately after the last cocaine SA session decreases subsequent cocaine-seeking. This effect suggests that cocaine-induced hyperactivity in PrL-pPVT neurons contributes to relapse.

Unexpectedly, we found that infusion of BDNF in rats with chemogenetically inhibited PrL-pPVT neurons increases relapse. We hypothesize that, when BDNF is infused into the PrL cortex, it prevents hM4Di inhibition of PrL-pPVT neurons and restores their native hyperactive state during early cocaine withdrawal, which in turn promotes long-term relapse. Such an action would be consistent with BDNF's ability to restore activity in the hypoactive PrL-NAc pathway after cocaine SA, thereby decreasing relapse. Thus, cocaine-induced PrL-NAc hypoactivity together with PrL-pPVT hyperactivity during early withdrawal drive longterm relapse propensity. Prevention of cocaine-induced suppression of pERK-related phosphoproteins in PrL cortex appears to be critical to BDNF's ability to decrease subsequent relapse (Whitfield et al., 2011; Go et al., 2016). However, the only other time point we have infused BDNF is after 1 week of abstinence, a time point at which BDNF has no effect on relapse (Berglind et al., 2007). A related question is whether hM4Di inhibition of the PrL cortex (and the PrL-pPVT pathway) can decrease cocaineseeking outside of the early intervention window that must be addressed by future studies. Notably, activity in pPVT neurons increases during relapse triggered by discrete cocaine-conditioned stimuli (Matzeu et al., 2015, 2017; Kuhn et al., 2018). Given that the PrL cortex is also known to drive relapse at these later time points in our SA model (McFarland and Kalivas, 2001; Moorman et al., 2015; Stefanik et al., 2016), and provides a glutamatergic input to the pPVT (Kirouac, 2015), it is possible the hM4Dimediated reduction of cocaine-seeking in the PrL-pPVT pathway observed in this study would also be effective immediately before a relapse episode. Future studies will explore this hypothesis and determine the neuroadaptations in these distinct PrL pathways during early withdrawal that underlie pathway-selective regulation of cocaine-seeking. 


\section{References}

Augur IF, Wyckoff AR, Aston-Jones G, Kalivas PW, Peters J (2016) Chemogenetic activation of an extinction neural circuit reduces cue-induced reinstatement of cocaine-seeking. J Neurosci 36:10174-10180. CrossRef Medline

Berglind WJ, See RE, Fuchs RA, Ghee SM, Whitfield TW Jr, Miller SW, McGinty JF (2007) A BDNF infusion into the medial prefrontal cortex suppresses cocaine-seeking in rats. Eur J Neurosci 26:757-766. CrossRef Medline

Berglind WJ, Whitfield TW Jr, LaLumiere RT, Kalivas PW, McGinty JF (2009) A single intra-PFC infusion of BDNF prevents cocaine-induced alterations in extracellular glutamate within the nucleus accumbens. J Neurosci 29:3715-3719. CrossRef Medline

Browning JR, Jansen HT, Sorg BA (2014) Inactivation of the paraventricular thalamus abolishes the expression of cocaine conditioned place preference in rats. Drug Alcohol Depend 134:387-390. CrossRef Medline

Chang JY, Janak PH, Woodward DJ (1998) Comparison of mesocorticolimbic neuronal responses during cocaine and heroin self-administration in freely moving rats. J Neurosci 18:3098-3115. CrossRef Medline

Dennis TS, Jhou TC, McGinty JF (2018) Cocaine self-administration and time-dependent decreases in prelimbic activity. bioRxiv 255455. CrossRef

Dittgen T, Nimmerjahn A, Komai S, Licznerski P, Waters J, Margrie TW, Helmchen F, Denk W, Brecht M, Osten P (2004) Lentivirus-based genetic manipulations of cortical neurons and their optical and electrophysiological monitoring in vivo. Proc Natl Acad Sci U S A 101:18206-18211. CrossRef Medline

Do-Monte FH, Minier-Toribio A, Quiñones-Laracuente K, Medina-Colón EM, Quirk GJ (2017) Thalamic Regulation of Sucrose-seeking during Unexpected Reward Omission. Neuron 94:388-400.e4. CrossRef Medline

Gabbott PL, Warner TA, Jays PR, Salway P, Busby SJ (2005) Prefrontal cortex in the rat: projections to subcortical autonomic, motor, and limbic centers. J Comp Neurol 492:145-177. CrossRef Medline

Go BS, Barry SM, McGinty JF (2016) Glutamatergic neurotransmission in the prefrontal cortex mediates the suppressive effect of intra-prelimbic cortical infusion of BDNF on cocaine-seeking. Eur Neuropsychopharmacol 26:1989-1999. CrossRef Medline

Gomez JL, Bonaventura J, Lesniak W, Mathews WB, Sysa-Shah P, Rodriguez LA, Ellis RJ, Richie CT, Harvey BK, Dannals RF, Pomper MG, Bonci A, Michaelides M (2017) Chemogenetics revealed: DREADD occupancy and activation via converted clozapine. Science 357:503-507. CrossRef Medline

Hamlin AS, Clemens KJ, Choi EA, McNally GP (2009) Paraventricular thalamus mediates context-induced reinstatement (renewal) of extinguished reward seeking. Eur J Neurosci 29:802-812. CrossRef Medline

He J, Gong H, Luo Q (2005) BDNF acutely modulates synaptic transmission and calcium signalling in developing cortical neurons. Cell Physiol Biochem 16:69-76. CrossRef Medline

James MH, Dayas CV (2013) What about me? The PVT: a role for the paraventricular thalamus (PVT) in drug-seeking behavior. Front Behav Neurosci 7:18. CrossRef Medline

James MH, Charnley JL, Jones E, Levi EM, Yeoh JW, Flynn JR, Smith DW, Dayas CV (2010) Cocaine- and amphetamine-regulated transcript (CART) signaling within the paraventricular thalamus modulates cocaine-seeking behaviour. PLoS One 5:e12980. CrossRef Medline

Kafitz KW, Rose CR, Thoenen H, Konnerth A (1999) Neurotrophin-evoked rapid excitation through TrkB receptors. Nature 401:918-921. CrossRef Medline

Kalivas PW, Volkow ND (2005) The neural basis of addiction: a pathology of motivation and choice. Am J Psychiatry 162:1403-1413. CrossRef Medline

Kirouac GJ (2015) Placing the paraventricular nucleus of the thalamus within the brain circuits that control behavior. Neurosci Biobehav Rev 56:315-329. CrossRef Medline

Koob GF, Volkow ND (2016) Neurobiology of addiction: a neurocircuitry analysis. Lancet Psychiatry 3:760-773. CrossRef Medline

Kowianski P, Lietzau G, Czuba E, Waskow M, Steliga A, Morys J (2018) BDNF: a key factor with multipotent impact on brain signaling and synaptic plasticity. Cell Mol Neurobiol 38:579-593. CrossRef Medline

Kuhn BN, Klumpner MS, Covelo IR, Campus P, Flagel SB (2018) Transient inactivation of the paraventricular nucleus of the thalamus enhances cueinduced reinstatement in goal-trackers, but not sign-trackers. Psychopharmacology (Berl) 235:999-1014. CrossRef Medline
Leal G, Afonso PM, Salazar IL, Duarte CB (2015) Regulation of hippocampal synaptic plasticity by BDNF. Brain Res 1621:82-101. CrossRef Medline

Leal G, Bramham CR, Duarte CB (2017) BDNF and hippocampal synaptic plasticity. Vitam Horm 104:153-195. CrossRef Medline

Li S, Kirouac GJ (2012) Sources of inputs to the anterior and posterior aspects of the paraventricular nucleus of the thalamus. Brain Struct Funct 217:257-273. CrossRef Medline

MacLaren DA, Browne RW, Shaw JK, Krishnan Radhakrishnan S, Khare P, España RA, Clark SD (2016) Clozapine N-oxide administration produces behavioral effects in Long-Evans rats: implications for designing DREADD experiments. eNeuro 3:ENEURO.0219-16.2016. CrossRef Medline

Mahler SV, Vazey EM, Beckley JT, Keistler CR, McGlinchey EM, Kaufling J, Wilson SP, Deisseroth K, Woodward JJ, Aston-Jones G (2014) Designer receptors show role for ventral pallidum input to ventral tegmental area in cocaine-seeking. Nat Neurosci 17:577-585. CrossRef Medline

Martin-Fardon R, Boutrel B (2012) Orexin/hypocretin (Orx/Hcrt) transmission and drug-seeking behavior: is the paraventricular nucleus of the thalamus (PVT) part of the drug-seeking circuitry? Front Behav Neurosci 6:75. CrossRef Medline

Matzeu A, Weiss F, Martin-Fardon R (2015) Transient inactivation of the posterior paraventricular nucleus of the thalamus blocks cocaine-seeking behavior. Neurosci Lett 608:34-39. CrossRef Medline

Matzeu A, Cauvi G, Kerr TM, Weiss F, Martin-Fardon R (2017) The paraventricular nucleus of the thalamus is differentially recruited by stimuli conditioned to the availability of cocaine versus palatable food. Addict Biol 22:70-77. CrossRef Medline

McFarland K, Kalivas PW (2001) The circuitry mediating cocaine-induced reinstatement of drug-seeking behavior. J Neurosci 21:8655-8663. CrossRef Medline

Millan EZ, Ong Z, McNally GP (2017) Paraventricular thalamus: gateway to feeding, appetitive motivation, and drug addiction. Prog Brain Res 235: 113-137. CrossRef Medline

Moorman DE, James MH, McGlinchey EM, Aston-Jones G (2015) Differential roles of medial prefrontal subregions in the regulation of drugseeking. Brain Res 1628:130-146. CrossRef Medline

Nathanson JL, Yanagawa Y, Obata K, Callaway EM (2009) Preferential labeling of inhibitory and excitatory cortical neurons by endogenous tropism of adeno-associated virus and lentivirus vectors. Neuroscience 161: 441-450. CrossRef Medline

National Institutes of Health (2011) Guide for the care and use of laboratory animals, Ed 8. Washington, DC: National Academies.

Otis JM, Namboodiri VM, Matan AM, Voets ES, Mohorn EP, Kosyk O, McHenry JA, Robinson JE, Resendez SL, Rossi MA, Stuber GD (2017) Prefrontal cortex output circuits guide reward seeking through divergent cue encoding. Nature 543:103-107. CrossRef Medline

Povysheva NV, Johnson JW (2012) Tonic NMDA receptor-mediated current in prefrontal cortical pyramidal cells and fast-spiking interneurons. J Neurophysiol 107:2232-2243. CrossRef Medline

Saloman JL, Scheff NN, Snyder LM, Ross SE, Davis BM, Gold MS (2016) Gi-DREADD expression in peripheral nerves produces ligand-dependent analgesia, as well as ligand-independent functional changes in sensory neurons. J Neurosci 36:10769-10781. CrossRef Medline

Stefanik MT, Kupchik YM, Kalivas PW (2016) Optogenetic inhibition of cortical afferents in the nucleus accumbens simultaneously prevents cueinduced transient synaptic potentiation and cocaine-seeking behavior. Brain Struct Funct 221:1681-1689. CrossRef Medline

Tervo DG, Hwang BY, Viswanathan S, Gaj T, Lavzin M, Ritola KD, Lindo S, Michael S, Kuleshova E, Ojala D, Huang CC, Gerfen CR, Schiller J, Dudman JT, Hantman AW, Looger LL, Schaffer DV, Karpova AY (2016) A designer AAV variant permits efficient retrograde access to projection neurons. Neuron 92:372-382. CrossRef Medline

Whitfield TW Jr, Shi X, Sun WL, McGinty JF (2011) The suppressive effect of an intra-prefrontal cortical infusion of BDNF on cocaine-seeking is trk receptor and extracellular signal-regulated protein kinase mitogenactivated protein kinase dependent. J Neurosci 31:834-842. CrossRef Medline

Young CD, Deutch AY (1998) The effects of thalamic paraventricular nucleus lesions on cocaine-induced locomotor activity and sensitization. Pharmacol Biochem Behav 60:753-758. CrossRef Medline 